時系列 PIV 解析による回転二円板間大規模渦構造の研究

\author{
古江 正人 ${ }^{\circ}$ (同志社大学), 菅原 之宽 (同志社大学) \\ 舟木 治郎 (同志社大学), 平田 勝哉 (同志社大学)
}

\title{
Of Large-Scale Vortical Structures Between Rotating Disks By Continuous PIV
}

\author{
Masato FURUE, Nobuhiro SUGAWARA, Jiro FUNAKI and Katsuya HIRATA
}

\begin{abstract}
In this study, we investigate the flow between co-rotating disks in a stationary cylindrical enclosure. Here, the gap between disks is much narrower than disk radius. This flow is often non-axisymmetrical and complicated. This flow sometimes induces magnetic-head oscillations in disk storage drives of PCs. Then, we carry out flow visualisations using a high-speed camera, and time-continuous quasi-three-dimensional PIV (Particle Image Velocimetry) analyses. As a result, we confirm a pair of toroidal vortex structures near the cylindrical enclosure on the $r z$ plane. We show the toroidal structures on a quasi-three-dimensional space $r z t$. Here, $t$ is the time. By this visualisation technique, we can easily and clearly see the toroidal structures. We can confirm that the vortex structures hardly fluctuate.
\end{abstract}

Keywords: PIV, rotating disk, toroidal vortex, qausi-three-dimensional PIV

\section{1. 緒言}

本研究では, 静止外周壁内の同軸で共回転する同径の二 円板間の流れについて研究を行なった，円板間隙は円板径 よりも十分に小さいこの流れは，しばしば非軸対称で, 複雑 なもので, 実際にパソコン等に用いられる磁気ディスク装置な どで発生し，磁気ヘッドの振動などの原因となっている. その ためこの流れを把握することが必要である.

この流れを解明するために様々な研究が行なわれてきた。 Lennemannらは(1987), 非軸対称な周方向モードについて 研究を行った. Herreroらは (1999) は, 三次元数值シミュレ ーションにより, 軸方向モードの分類を行なった.

本研究ではモデル装置を用い, ハイスピードカメラにより円 板間の流れをPIV(Particle Image Velocimetry)解析し,さ らに時間軸を加えた擬似三次元空間で渦構造を可視化し t.

\section{2. 実験方法}

\section{1 実験装置}

Fig.1 は実験装置の概略図である. 円板間の可視化がで
きるように, 外周壁及び回転円板はアクリル製である. 静止外 周壁の周りに，アクリル製の直方体容器を設㯰することにより， 可視化を行った際の外周壁によるひずみを取り除いた。作 動流体は, 水を使用した.

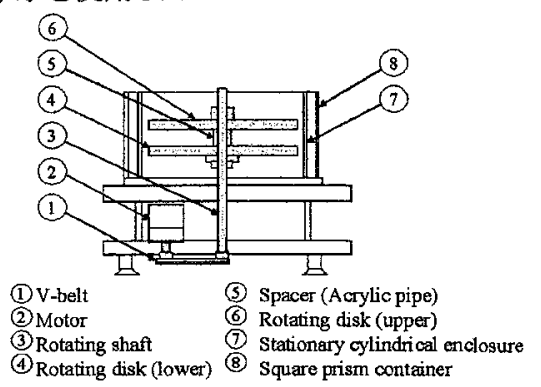

Fig.1 Schematic diagram of model.

\section{2 パラメータ}

重要なパラメータを下記に示す. (Fig.2 参照) また座標 系は円柱座標系 $(r, \theta, z)$ を用いる.

円板端の速度を代表速度にとった回転レイノルズ数は，

$$
R e=\frac{\omega R_{\mathrm{d}}^{2}}{v} .
$$


$R e=3.6 \times 10^{3}$ (円板回転速度 $1.5 \mathrm{rpm}$ )を用いた.

円板間隙比は

$$
\delta=\frac{G}{R_{\mathrm{d}}} .
$$

$\delta=0.09$ を用いた. 無次元静止外周壁半径は

$$
\lambda=\frac{R_{\mathrm{w}}}{R_{\mathrm{d}}} .
$$

本研究では, $\lambda=1.0,\left(R_{\mathrm{d}}-R_{\mathrm{w}}\right) / R_{\mathrm{d}}=0.004$. また円板の一回 転に要する時間を $t_{\mathrm{d}}$ とする. 今回, 軸方向モード I , 周方向 モード 0で赛験を行った. ${ }^{112)}$

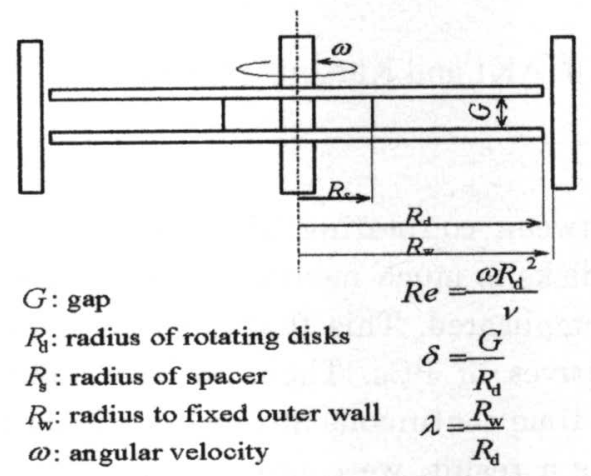

Fig.2 Definition of governing parameters.

\section{4 流れの可視化とPIV 解析}

本研究では軸方向 $(r z)$ 断面之周方向 $(r \theta)$ 断面の PIV 解 析を行った. 可視化には, 架橋ポリエチレン粒子に蛍光塗料 を付加した蛍光粒子を用いて, スリット光を円板側面から軸 方向断面に, あるいは周方向断面に照射して可視化を行っ た. 軸方向断面の可視化においては円板側部より,また周 方向断面の可視化においては円板上部よりハイスピードカメ ラにより撮影した. また軸方向断面の PIV 解析結果より時間 軸を加えた擬似三次元空間で, 流れの可視化を試みた.

\section{3. 実験結果及び考察}

軸方向断面の PIV 解析結果を Fig.3に示す. Fig.3 より, 時間的な変動は無視できないが, 外周壁付近で生じるトーラ ス状の渦構造がどの瞬間も観察できる. さらに渦度が逆でほ ぼ上下対称であることもわかる. よって文献 1)より,この流れ は軸方向モード I とみなせる.

この軸方向断面の PIV 解析を高速度カメラにより短時間 間隔で実施することより, 時間軸を加えた擬似三次元空間で の結果として示すことができる. (Fig.4 参照) 外周壁付近の 渦構造はほとんど変動しないことが確認できる. なお,この方 法は, より複雑なモードでの流れ構造の理解に有用である.

\section{4. 結言}

1. 外周壁付近で生じるトーラス状の渦構造は観察すること に成功した. 渦構造は時間的に変動するが, 大まかな卜 ーラス構造は保たれている.
2. 高速度カメラを用いた連続 PIVにより,トーラス状の渦構 造を擬似三次元的に示すことができた。

参考文献

1) Herrero,J,A,C, Giralt,F and Humphrey,J,A,C : Influence of the geometry on the structure of the flow between a pair of corotating disks, Physics of Fuluids, Vol11, No.1 (1999) pp. 88-96

2) Lennemann,E : Aerodynamic aspects of disk files, IBM J.Res.Dev., Vol.16, No.6 (1974) pp.480-488.

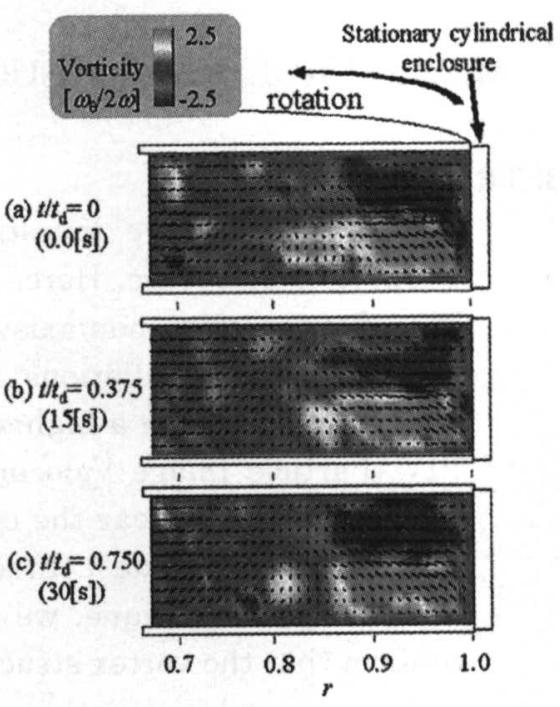

Fig.3 Velocity vectors and vorticity $\omega_{\theta}$ on the $r z$ plane $\left(R e=3.6 \times 10^{3}, \delta=0.09, \lambda=1.0\right.$, mode I -0$)$.

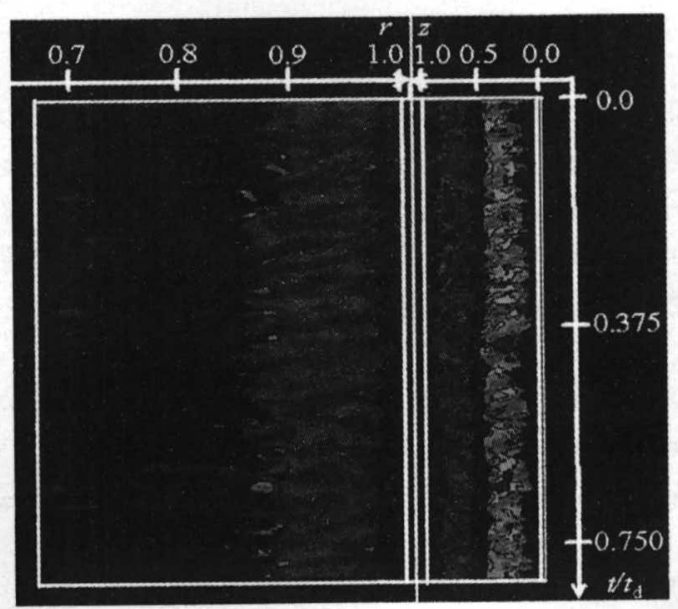

Fig.4 Iso-vorticity surface of $\omega_{\theta}$ on the r-z plane at $t t t_{\mathrm{d}}=$ 0.00-0.825 $\left(R e=3.6 \times 10^{3}, \delta=0.09, \lambda=1.0\right.$, mode I -0$)$. 